\title{
Overview of Mindset and Attitudes of 2017 FK UKI Students about Euthanasia
}

\author{
Suryo Wijoyo \\ Medical Faculty, Universitas Kristen Indonesia, Jakarta
}

\begin{abstract}
Medical workers sometimes receive Euthanasia requests from patients or their families. In Indonesia, Euthanasia is still a considerable controversy, especially about how it counters norms that have been attached in Indonesia. This study aims to see the illustration of mindset and attitude of Medical Students of Christian University of Indonesia 2017 generation regarding Euthanasia. This study was conducted in August-November 2018 using the descriptive survey method, with data from questionnaires given to 120 samples of Medical Students of Universitas Kristen Indonesia 2017 generation. The sample was picked using simple random sampling. The univariate analysis result shows $26,9 \%$ of respondents agreed to legalization and support from the medical workers, and $55 \%$ of respondents agreed to the act of Euthanasia.
\end{abstract}

Keywords: Euthanasia, mindset, attitude

\section{INTRODUCTION}

Data on the most common causes of death in the world, including ischemic heart disease, stroke, chronic obstructive pulmonary disease, lower respiratory tract infections, Alzheimer's and dementia, cancer of the respiratory tract, diabetes mellitus, traffic accidents, diarrhoea, and tuberculosis. Based on this data, it can be seen that the most common causes of death in the world are caused by chronic diseases that are physically draining and mentally [1; 2 ; 3].

Based on this condition, patients who have suffered from chronic diseases are forced to face the worst possibilities that can affect the patient's mindset towards the quality of his own life. In this situation, it is not uncommon for medical personnel to be asked to end the patient's suffering. This request can come from the sufferer himself or family members who can no longer see blood-related people suffer. This situation is known as Euthanasia.

Euthanasia is the intentional termination of the life of a person who suffers from a disease accompanied by relatively severe and incurable pain $[4 ; 5]$. Similar to the purpose of Euthanasia itself is Psychian Assisted Suicide (PAS), a condition where the patient asks a doctor for help to accompany him to end his own life. What distinguishes it is that where a doctor carries out the perpetrator of the action is called Euthanasia. Meanwhile, if the patient himself takes his own life, it is called PAS.

One example of a recent case that has spread much criticism in the community is the case of Euthanasia, with the youngest patient being 17 years old in Belgium. The name and history of the patient's exact illness are kept secret, but the information that gets to the public is that the patient is suffering from a "critical illness". It was confirmed by Professor Wim Distelmans, head of the Belgian Federal Committee for Monitoring and Evaluation of Euthanasia, that the issue of minors receiving assistance to perform Euthanasia had been reported to his committee a week before this confirmation was given, namely in September 2016. This news garnered many 
controversies. Because it is against religion, and the medical community does not approve of Euthanasia performed on children under 18 years $[6 ; 7 ; 8]$.

After the Netherlands became the first country to legalize Euthanasia in April 2002, Belgium followed suit in September 2002. Belgian law that year only covered the legality of voluntary Euthanasia and did not include PAS [9; 10]. Then in 2014, the law on Euthanasia was renewed by allowing Euthanasia to children who were sick with criteria that could no longer be helped with medical assistance. Countries that have also legalized Euthanasia and PAS include Luxembourg and Colombia. The only countries that legalize PAS are Belgium, Canada, Finland, Germany, Switzerland and the 5 States of the United States: Oregon, Washington, Vermont, Montana and New Mexico.

With the development of technology that can disseminate information to the broader community, Euthanasia and PAS have become quite hot topics to be discussed. Pros and cons were raised from various elements of society with various speculative backgrounds on Euthanasia.

Based on the description above, this study answers the research problem as follows: "What are the mindsets and attitudes of students of the Faculty of Medicine, Indonesian Christian University (FK UKI) towards Euthanasia?" To know the views, mindsets and attitudes of the 2017 UKI FK students towards Euthanasia.

\section{LITERATURE REVIEW}

Euthanasia comes from the word 'eu', which means good and 'Thanatos which means death, making Euthanasia in the sense of a good death. Euthanasia is the intentional termination of a person's life suffering from a disease accompanied by relatively severe and incurable pain $[11 ; 12$; 13]. In the process of Euthanasia carried out on patients who are under medical care by doctors, there is a killing based on "mercy" because that is why in English, which Richard Lamerton put forward in the 20th century, Euthanasia is interpreted as mercy killing, which in the sense of this mercy means mercy $[14 ; 15]$.

Euthanasia is also often called Physician-Assisted Suicide, which we have discussed has different meanings and methods. Where Euthanasia means that we in the medical profession help patients directly realize their desires consciously, while in PAS, we consciously help patients who will carry out their wishes by their own hands.

From the data collected and reported to the Belgian government, the death rate for Euthanasia increased rapidly from January 1, 2003 (counting statistics from 2003 because Euthanasia was legalized in Belgium starting in September 2002) to December 31, 2013, with a total of 8725 cases. The number has increased annually, starting from 235 cases in $2003(0.2 \%$ of total deaths) to 1807 cases in 2013 (1.7\% of total deaths). An extra note that needs to be emphasized is that the data presented are only those reported to the Belgian government and cover more than half of the estimated Euthanasia cases [16; 17].

The table above shows a rapid development from when Euthanasia was legalized in Belgium until ten years later. In the last six years, there was a drastic increase from 129 cases in 2007 to 632 in 2013. The age range specifications that experienced an increase were 80 years and over, with an initial 40 of 235 cases (17\%) in 2003 to 632 of 1807 cases (35\%) in 2013. The percentage of the 60-79 age group remained static at the interval of 48.5$56.8 \%$. The age group of 18-59 years experienced a decrease in line with the increase in the group over 80 years. Starting with an initial percentage of $43.5 \%$ in 2003 and ending with $16.5 \%$ in 2013 . Overall there was an increase of $760 \%$ from the number of initial cases in 2003 to 2013.

The Netherlands itself has a higher number of cases than Belgium. Data were collected starting in 2003 because the legalization of Euthanasia in the Netherlands began in April 2002. The 
increase in Euthanasia cases from 2003 to 2013 had a percentage increase of $276 \%$, less than half the increase in Belgium. Meanwhile, the percentage increase until 2015 was 324\%, starting from 1,626 cases in 2003 to 5,277 in 2015. Data from PAS and Euthanasia in the Netherlands show a tendency for patients to choose Euthanasia over PAS more than 20 times $[18 ; 19]$.

Based on data from the Belgian and Dutch governments, it was found that the motivation of patients to take Euthanasia was primarily based on the fact that the patient had a terminal illness for reasons that were divided into [20; 21]: a) Suffering physically and mentally; b) Suffering only physically, and c) Suffering only mentally.

The percentage of patients suffering physically and mentally increased from 2003 with $50.6 \%$ to 2013 with a figure of $63.5 \%$. The decline in the patients' number suffering physically and mentally was accompanied by a decrease in the patients who suffered only physically from $42 \%$ in 2003 to $28.9 \%$ in 3013. In contrast, patients' cases who suffered mentally remained in the range of $5 \%$ with initial starting from $6.9 \%$ in 2003 to 7.5 in 2013 with a decline to the lowest point of $1 \%$ in 2007 [22].

Donna A Champeun's research in 1994 on the factors that influence individual assessments of Voluntary Euthanasia and PAS with a total population of 825 people found that the most significant factor in making this decision was the fear of burdening others (family and closest people). The lack of research on the difference in motivation to perform Euthanasia with PAS makes the same variable challenging to distinguish, which prompted him to look for it. From the questionnaire that he distributed, it was found that most people who supported the adoption of Euthanasia occurred in cases of people with cancer and Amyotrophic Lateral Sclerosis (ALS). The conclusion is that in people with ALS and cancer, the quality of life in the future is difficult to determine and brings the patient's mind to fear of burdening those around him. The exciting thing is that religion is one of the most significant factors in respondents who reject the act of Euthanasia, among other factors [23; 24].

Donna Champion found differences in opinion about the importance of the factors most frequently stated by the respondents. From the calculation of 807 respondents, the average score of views on the influence of three factors: fear of death, fear of dependence (on people around) and trust. Fear of death and dependence are more significant than unaffected, while belief has the highest no effect, then doubtful and followed by affected. Research conducted in Oregon in 1995 shows how religion influences decision-making factors. Although it has the most miniature percentage effect, religion or belief still contributes numbers to the study results.

In general, there are two types of Euthanasia which are grouped from actions, wishes of certain parties and perpetrators of these actions:

Passive Euthanasia, which is intentionally not providing medical assistance to maximize the patient's life span. Passive Euthanasia is divided into three classifications [25; 26]: a) voluntary passive Euthanasia is a classification where the patient himself requests that the medical action to be taken against him is cancelled or not continued; b) Non-voluntary passive Euthanasia, this includes cases where a person does not know precisely what action the incompetent patient wants, but there is a definite reason to believe that the patient wants to die at that time; c) Involuntary passive Euthanasia, is when the patient does not want to stop the medical action against him, but according to other people the action is the best thing than continuing it.

Active Euthanasia, which is an action that is done intentionally to end or shorten the patient's life. Active Euthanasia is further differentiated into groups of initial goals that underlie the action of Euthanasia: a) Voluntary active Euthanasia is the administration of lethal doses of drugs at the request of the patient himself; b) Non- 
voluntary active Euthanasia is the administration of lethal doses of drugs to incompetent patients based on the patient's request before his condition worsens for Euthanasia if he is already in a state of suffering; and c) Involuntary active Euthanasia, is where the patient's family, friends or personal doctor decides to end the patient's life even though they know that the patient does not want to die in this condition.

Attitude component: Attitude is included in the aspect of thinking that will shape the mindset of each individual on specific topics. This mindset will then affect the attitude that humans will take to respond to events or incidents. Attitudes will determine human behaviour regarding relationships in assessing particular objects and providing direction for further actions. According to Baron and Byrne, attitudes contain three components that form the basic structure of attitudes, namely [27]: a) Cognitive (perceptual) components, namely components related to knowledge, views, beliefs and matters relating to how a person places his or her perception; b) The affective (emotional) component, which is a component related to personal feelings towards the attitude object. Pleasure is defined as a positive response and attitude, while displeasure is a negative attitude; and c) the conative component (behaviour or action component), the component related to the tendency to act on an object that needs to be addressed. This component shows the intensity of the attitude, which is how big or small the tendency of a person's actions or behaviour towards the object of attitude is.

Attitude is an essential thing in psychology, especially social psychology. Social psychology places attitudes as central [28; 29]. This opinion seems reasonable if it is seen the importance of attitude in everyday human behaviour and actions. A person's attitude will affect the person's behaviour in response to something. Attitude is influenced by several factors that can determine attitude change. The factors that can influence the formation of attitudes are: a) Personal experience. To form the basis of attitude formation, the personal experience must leave a strong impression. It involves an emotional state so that the appreciation of the experience is more profound and lasts longer; b) Culture. Culture has a significant influence on the formation of a person's attitude. Without us realizing it, culture has instilled a line of influence on our attitudes towards various problems. Culture has also coloured attitudes and gave a style of experience to individuals who are members of the community they care for. Only an individual personality that has been established and strong can diminish the dominance of culture in the formation of individual attitudes; c) Other people who are considered essential. Other people around us are one of the social components that influence our attitudes. A person will imitate and act the same as other people if deemed worthy of being a role model; d) Mass Media. The influence of the mass media is not too significant indirect individual interaction, but informing and changing attitudes, the role of the mass media is not tiny. In delivering information as to its primary task, the mass media also carry messages that contain suggestions that can direct one's opinion; e) Educational Institutions and Religious Institutions. Educational institutions and religious institutions as a system influence attitudes because they lay the basis for understanding and moral concepts in individuals. Moral concepts and religious teachings greatly determine belief systems, so it is not surprising that these concepts play a role in determining individual attitudes, and $\mathrm{f}$ ) the influence of emotional factors. A person's attitude formation is not determined by one's environmental situation and personal experience, but an attitude is a statement based on an emotion that serves as a channelling frustration or diversion of the ego's defence mechanism. An attitude based on emotion is prejudice, namely an intolerant attitude towards a group of people. 


\section{RESEARCH METHOD}

The method used in this research is a descriptive survey. The descriptive research method is a method that examines a group, a condition, or an event in the present to make a systematic, factual and accurate description, picture or painting of the facts, characteristics and relationships between the phenomena being investigated. The survey method used is to obtain the results of reports on Euthanasia directly from the group to be studied, namely the 2017 UKI Medical Faculty students. The data is obtained in the form of primary data from questionnaires. This research was carried out at the UKI Medical Faculty, with data collection carried out in August-November 2018. The research population was preclinical students of the UKI Medical Faculty. Affordable for 2017 students. The population in the study amounted to 172 people. The research sample is the 20162017 Indonesian Christian University Faculty of Medicine students. Calculation of the sample size is carried out using the Simple Random Sampling formula:

$$
\begin{aligned}
& n=\frac{N}{1+N(d)^{2}} \\
& n=\frac{172}{1+172(0.05)^{2}} \\
& n=\frac{172}{1,43} \\
& n=120
\end{aligned}
$$

Information:

$\mathrm{n}=$ sample size

$\mathrm{N}=$ population size $=172$

$\mathrm{d}=$ desired level of accuracy $=0.05$

With the desired level of accuracy is $95 \%$, the relative accuracy level is 5\% (converted into the decimal form). So the number of samples obtained is 120 people.

The data obtained will be converted into tabular form and then processed using statistical test software. In this study, researchers used SPSS v.23. The steps of the data processing process are as follows: a) Editing, editing immediately after the questionnaire is entered so that if there is a lack of data, the researcher can immediately correct it with the relevant respondents; b)
Coding, giving symbols, codes or numbers to the data to be processed to make it easier when the data is processed through software; c) Data Entry, data that has been collected is then entered into the software so that it can then be processed; d) Cleaning, re-checking the entered data and recorrecting it if there is something that needs to be corrected; and e) Output, the stage where the data has received the results of the analysis provided by the statistical test software.

\section{RESULT AND DISCUSSION}

The affordable population is FK UKI students class 2017, with a total number of respondents as many as 120 people. The frequency distribution of respondents based on age in the FK UKI class of 2017 is explained as follows: The number of respondents aged 17 years is six people (5\%), 18 years old is 23 people (19.2\%), 19 years old is 74 people $(61,7 \%)$, age 20 years as many as 17 people (14.2\%). Thus, it can be seen that most of the 2017 UKI FK students are 19 years old (see table 1).

Table 1. Age Characteristics of Respondents
\begin{tabular}{|l|l|l|}
\hline Age & Number & $\%$ \\
\hline 17 & 6 & 5 \\
\hline 18 & 23 & 19,2 \\
\hline 19 & 74 & 61,7 \\
\hline 20 & 17 & 14,2 \\
\hline Total & 120 & 100 \\
\hline
\end{tabular}

The frequency distribution of respondents by gender in the FK UKI class of 2017 is explained as follows: the number of male respondents is 51 (42.5\%), and female respondents are 69 (57.5\%).

Table 2. Gender Characteristics of Respondents

\begin{tabular}{|l|l|l|}
\hline Gender & Number & \% \\
\hline Male & 51 & 42,5 \\
\hline Female & 69 & 57,5 \\
\hline Total & 120 & 100 \\
\hline
\end{tabular}

Thus, it can be seen that most of the 2017 UKI FK students are female (see table 2). The frequency distribution of respondents based on ethnicity/ethnicity in the FK UKI class of 2017 is explained as follows: the most significant number of respondent tribes is the Batak ethnic group, 
as many as 32 people (26.7\%), the Javanese as many as 25 people (20.8\%), the Toraja ethnic group as many as nine people (7.5\%), ethnic Chinese as many as nine people (7.5\%), ethnic Manado as many as eight people (6.7\%), ethnic Papuan as many as seven people (5.8\%), ethnic Balinese as many as four people ( $3.3 \%)$, the Dayak tribe as many as four people (3.3\%), the Timor Leste tribe as many as four people (3.3\%), the Flores Tribe as many as three people (2.5\%), the Maluku Tribe as many as three people (2.5\%), two people from the Betawi people (1.7\%), the Minang tribe as many as two people (1.7\%), the Sundanese as many as two people (1.7\%), and the Ambonese, Nias, NTT, Padang tribes, Rote and Sumatra each as many as one person (0.8\%). Thus, most of the 2017 UKI FK students came from the Batak Tribe (see table 3).

Table 3. Characteristics of Respondents' Ethnicity

\begin{tabular}{|c|c|c|}
\hline Ethnic group & Number & $\%$ \\
\hline Batak & 32 & 26,7 \\
\hline Jawa & 25 & 20,8 \\
\hline Tionghoa & 9 & 7,5 \\
\hline Toraja & 9 & 7,5 \\
\hline Manado & 8 & 6,7 \\
\hline Papua & 7 & 5,8 \\
\hline Bali & 4 & 3,3 \\
\hline Dayak & 4 & 3,3 \\
\hline Timor Leste & 4 & 3,3 \\
\hline Flores & 3 & 2,5 \\
\hline Maluku & 3 & 2,5 \\
\hline Betawi & 2 & 1,7 \\
\hline Minang & 2 & 1,7 \\
\hline Sunda & 2 & 1,7 \\
\hline Ambon & 1 & 0,8 \\
\hline Nias & 1 & 0,8 \\
\hline NTT & 1 & 0,8 \\
\hline Padang & 1 & 0,8 \\
\hline Rote & 1 & 0,8 \\
\hline Sumatra & 1 & 0,8 \\
\hline Total & 120 & 100 \\
\hline
\end{tabular}

The frequency distribution of respondents based on religion in the FK
UKI class of 2017 is explained as follows: the number of respondents who are Protestant Christians is 64 people (53.3\%), Catholic Christians are 29 people (24.2\%), Muslims are 23 people (19.2 \%), and Hindus as many as four people (3.3\%). Thus, the most religious adherents to the 2017 UKI FK students are Protestant Christians (see table 4).

Table 4. Characteristics of Respondents' Religion

\begin{tabular}{|l|l|l|}
\hline Religion & Number & \% \\
\hline Protestant & 64 & 53,3 \\
\hline Catholic & 29 & 24,2 \\
\hline Islam & 23 & 19,2 \\
\hline Hindu & 4 & 3,3 \\
\hline Total & 120 & 100 \\
\hline
\end{tabular}

The frequency distribution of respondents based on attitudes towards Euthanasia in the FK UKI class of 2017 is explained as follows: the number of students who were judged to agree with Euthanasia was 66 people (55\%), the number of students who had doubts about the act of Euthanasia was 47 people $(39.2 \%)$ and seven people (5.8\%).

Table 5. Overall Attitude towards Euthanasia

\begin{tabular}{|l|l|l|}
\hline Attitude & Number & \% \\
\hline Agree & 66 & 55 \\
\hline Doubtful & 47 & 39,2 \\
\hline Disagree & 7 & 5,8 \\
\hline Total & 120 & 100 \\
\hline
\end{tabular}

Table 5.1. Attitudes about Euthanasia by Age

\begin{tabular}{|l|l|l|l|l|l|l|}
\hline \multirow{2}{*}{ Attitude } & Age & \multicolumn{1}{|c|}{ Number } & \% \\
\cline { 2 - 6 } & $\mathbf{1 7}$ & $\mathbf{1 8}$ & $\mathbf{1 9}$ & $\mathbf{2 0}$ & & \\
\hline Less & 0 & 0 & 6 & 1 & 7 & 5,8 \\
\hline Enough & 3 & 9 & 28 & 7 & 47 & 39,2 \\
\hline Well & 3 & 14 & 40 & 9 & 66 & 55 \\
\hline Total & 6 & 23 & 74 & 17 & 120 & 100 \\
\hline
\end{tabular}

Table 5.2. Total Attitudes on Euthanasia by Gender

\begin{tabular}{|l|l|l|l|l|}
\hline \multirow{2}{*}{ Attitude } & Number & \multirow{2}{*}{ Number } & \% \\
\cline { 2 - 3 } & Male & Female & & \\
\hline Less & 4 & 3 & 7 & 5,8 \\
\hline Enough & 20 & 27 & 47 & 39,2 \\
\hline Well & 27 & 39 & 66 & 55 \\
\hline Total & 51 & 69 & 120 & 100 \\
\hline
\end{tabular}

Table 5.3. Total Attitudes on Euthanasia by Ethnicity

\begin{tabular}{|l|l|l|l|l|l|}
\hline \multirow{2}{*}{ Ethnicity Group } & \multicolumn{2}{|l|}{ Number } & \multirow{2}{*}{ Number } & \multirow{2}{*}{} \\
\cline { 2 - 5 } & Agree & Doubtful & Disagree & & \\
\hline Ambon & 1 & 0 & 0 & 1 & 0,8 \\
\hline Bali & 2 & 2 & 0 & 4 & 3,3 \\
\hline Batak & 17 & 13 & 2 & 32 & 26,7 \\
\hline Betawi & 1 & 1 & 0 & 2 & 1,7 \\
\hline Dayak & 1 & 2 & 1 & 4 & 3,3 \\
\hline Flores & 2 & 1 & 0 & 3 & 2,5 \\
\hline Jawa & 11 & 12 & 2 & 25 & 20,8 \\
\hline Maluku & 2 & 1 & 0 & 3 & 2,5 \\
\hline Manado & 4 & 4 & 0 & 8 & 6,7 \\
\hline Minang & 2 & 0 & 0 & 2 & 1,7 \\
\hline
\end{tabular}




\begin{tabular}{|l|l|l|l|l|l|}
\hline \multicolumn{7}{|c|}{ Table 5.3. Continued... } \\
\hline Nias & 1 & 0 & 0 & 1 & 0,8 \\
\hline NTT & 1 & 0 & 0 & 1 & 0,8 \\
\hline Padang & 1 & 0 & 0 & 1 & 0,8 \\
\hline Papua & 5 & 2 & 0 & 7 & 5,8 \\
\hline Rote & 1 & 0 & 0 & 1 & 0,8 \\
\hline Sumatra & 0 & 1 & 0 & 1 & 0,8 \\
\hline Sunda & 1 & 1 & 0 & 2 & 1,7 \\
\hline Timor Leste & 3 & 1 & 0 & 4 & 3,3 \\
\hline Tionghoa & 4 & 4 & 1 & 9 & 7,5 \\
\hline Toraja & 6 & 2 & 1 & 9 & 7,5 \\
\hline Total & 66 & 47 & 7 & 120 & 100 \\
\hline
\end{tabular}

Table 5. 4. Total Attitudes on Euthanasia by Religion

\begin{tabular}{|c|c|c|c|c|c|c|}
\hline \multirow[t]{2}{*}{ Attitude } & \multicolumn{4}{|l|}{ Religions } & \multirow[t]{2}{*}{ Number } & \multirow[t]{2}{*}{$\%$} \\
\hline & Protestant & Catholic & Islam & Hindu & & \\
\hline Agree & 37 & 16 & 11 & 0 & 66 & 20 \\
\hline Doubtful & 23 & 11 & 11 & 2 & 47 & 79,2 \\
\hline Disagree & 4 & 2 & 1 & 2 & 7 & 0,8 \\
\hline Total & 64 & 29 & 23 & 4 & 120 & 100 \\
\hline
\end{tabular}

Table 6. Respondents' answers would be: Do you agree if terminal patients are given the freedom to choose to end their life (Euthanasia)?

\begin{tabular}{|l|l|l|}
\hline Response & Number & $\mathbf{\%}$ \\
\hline Strongly Agree & 15 & 12,5 \\
\hline Agree & 41 & 34,2 \\
\hline Doubtful & 38 & 31,7 \\
\hline Disagree & 18 & 15 \\
\hline Strongly Disagree & 8 & 6,7 \\
\hline Total & 120 & 100 \\
\hline
\end{tabular}

Table 7. Respondents' answers would be: Do you agree if Euthanasia is an alternative to end patient suffering?

\begin{tabular}{|l|l|l|}
\hline Response & Number & $\mathbf{\%}$ \\
\hline Strongly Agree & 10 & 8,3 \\
\hline Agree & 36 & 30 \\
\hline Doubtful & 31 & 25,8 \\
\hline Disagree & 28 & 23,3 \\
\hline Strongly Disagree & 15 & 12,5 \\
\hline Total & 120 & 100 \\
\hline
\end{tabular}

Respondents seemed to agree with the Euthanasia action carried out for those with a terminal illness, namely 41 people (34.2\%) and Euthanasia as an alternative to ending the suffering of patients as many as 36 people (30\%). Most of the explanations given by respondents were their goals because it was the patient who felt the suffering, so he had the right to choose his life path:

"Agreed because it did not cause any longlasting pain,"

"Agree than the patient suffers and lives not worth it,"

Respondents who answered outside agree did not provide many clear reasons why they did not agree with this.
Table 8. Respondents' answers would be: As medical personnel, we must help the person in order to end his life

\begin{tabular}{|l|l|l|}
\hline Response & Number & $\mathbf{\%}$ \\
\hline Strongly Agree & 5 & 4,2 \\
\hline Agree & 19 & 15,8 \\
\hline Doubtful & 42 & 35 \\
\hline Disagree & 32 & 26,7 \\
\hline Strongly Disagree & 22 & 18,3 \\
\hline Total & 120 & 100 \\
\hline
\end{tabular}

Table 9. Respondents' answers would be: Indonesian medical personnel may perform Euthanasia after receiving complete consent from the patient and the patient's family

\begin{tabular}{|l|l|l|}
\hline Response & Number & $\mathbf{\%}$ \\
\hline Strongly Agree & 20 & 16,7 \\
\hline Agree & 51 & 42,5 \\
\hline Doubtful & 31 & 25,8 \\
\hline Disagree & 13 & 10,8 \\
\hline Strongly Disagree & 5 & 4,2 \\
\hline Total & 120 & 100 \\
\hline
\end{tabular}

Although respondents tended to agree with the Euthanasia action, it was seen that 32 people $(26.7 \%)$ disagreed, and 22 people (18.3\%) strongly disagreed that medical personnel must help patients in order to end their lives. Many are of the opinion that medical personnel are allowed to perform Euthanasia after receiving full consent from the patient's family as many as 51 people (42.5\%).

Respondents who answered that they disagreed that medical personnel intervened tended to state the duties and responsibilities of doctors in maintaining a tarnished life, as follows:

"I do not agree because it is against our duty as medical personnel, which is to save patients' lives,"

"No, we do not have any right to end a patient's life," 
"I do not agree because I only give freedom to the patient but do not want to help end the patient's life,"

Respondents who explained their reasons regarding the assistance of medical personnel in the act of Euthanasia had a tendency that later changed to being allowed to perform Euthanasia after receiving full consent. However, there were those who still strongly objected to this. Meanwhile, respondents who answered refusing even though there was complete agreement tended to be respondents who chose to continue to refuse Euthanasia.

Table 10. Respondents' answers will be: As a medical student who will go into the field in the future, if your patient asks for Euthanasia, will you agree to it?

\begin{tabular}{|l|l|l|}
\hline Response & Number & $\mathbf{\%}$ \\
\hline Strongly Agree & 5 & 4,2 \\
\hline Agree & 18 & 15 \\
\hline Doubtful & 40 & 33,3 \\
\hline Disagree & 46 & 38,3 \\
\hline Strongly Disagree & 11 & 9,2 \\
\hline Total & 120 & 100 \\
\hline
\end{tabular}

Table 11. Respondents' answers would be: If Indonesia legalized Euthanasia, could doctors refuse not to do it?

\begin{tabular}{|l|l|l|}
\hline Response & Number & $\mathbf{\%}$ \\
\hline Strongly Agree & 32 & 26,9 \\
\hline Agree & 47 & 39,5 \\
\hline Doubtful & 31 & 26,1 \\
\hline Disagree & 6 & 5 \\
\hline Strongly Disagree & 3 & 2,5 \\
\hline Total & 119 & 100 \\
\hline
\end{tabular}

In addition to high support for Euthanasia actions that can be carried out with full consent, respondents are still in an attitude that does not agree to as medical personnel assisting Euthanasia actions. A total of 46 people (38.3\%) disagreed if he needed to perform Euthanasia during practice, and as many as 32 people (26.9\%) strongly agreed, and 47 people (39.5\%) agreed that doctors might refuse not to perform Euthanasia.

The responses and explanations regarding the two points above reap the most diverse responses, and the following is a description of the essay on whether the respondent will agree to the act of Euthanasia:

"I doubt it because this is his right, but that right is illegal in Indonesia,"
"No, because I personally definitely do not want to because it is against my conscience,"

"No, because I will do whatever it takes to help the patient,"

"I cannot bear it because I still hope for a cure,"

Responses tend to discuss the inner wars that do not have the heart to do it to patients and how the act of Euthanasia is against their conscience- the group of respondents who disagree because the legal umbrella does not protect the act of Euthanasia.

In the September 14 2018, interview with Mr Rev. President M.Th as the pastor in charge of the Evangelical Christian Church in Minahasa (GMIM), stated that: according to Christianity, the act of Euthanasia is an act of murder that is not justified for any reason because it has violated the norms of Christianity itself which are written in the ten laws of the Torah. Including "Don't kill".

The doctor's job is to do everything possible to do the best as long as the patient and the patient's family believe in what the doctor is doing, but if there is no longer anything that can be done to help prolong the patient's life, the responsibility of the doctor will be returned to his family. When the responsibility returns to the family, as a Christian family, we should not ask for Euthanasia, either with or without the patient's consent. Because Christians should pray and ask for God's help, not decide for themselves when other people's lives should end, and Christians must believe before the Lord takes the time of life, then there is still God's power at work.

Christians should believe in the miracle that God will give, and the miracle can come in two forms: the first is physical healing and healing in faith where the patient no longer has a body, but his soul has been lifted, which means God gives new life in hope. Therefore, these two miracles should still be believed to come and indeed be prepared by God because "life is gain, and death is gain". The difference between 
the legalization of Euthanasia abroad and in Indonesia according to religion and to those who consider it is in the patient's condition when he finds out that his disease cannot be cured. Christians will surrender to hope in the belief that miracles are real.

The resignation, according to Pdt. Presidents may or may not be quickly owned by those who have no faith or religion, tend to non-religious people give up their lives, while religious people, in this case, Christians, believe that there is life after death, namely eternal life with God and death is a door. The entry that we must not misuse by sinning is to take what is not ours because life belongs to Christ, and it is He who has the right to take it away.

In a November 2018 interview with Mr Uztad H Abu Hurairah Abdul Salam, MA, as the head of the executive body managing the Istiqlal Mosque, Islam thinks that if someone kills another person's life. It is the same as killing all humanity. In the view of Islam prohibits Euthanasia. In this regard, the Hadith of the Prophet Muhammad S.A.W. narrated by Annas r. a. as follows:

"That the Messenger of Allah said: Do not let any one of you beg for death because of the hardship that befell him. If it is essential for him to do so, then say the following prayer: O Allah! Extend my life, if it is better for me to live, and die when I should die." From the Hadith mentioned above, it is clearly stated that Euthanasia is prohibited in Islam.

In an interview September 152018 with. Bhikku Pabhajayo as a religious leader at Vihara Dhammacakka Jaya Jakarta stated that: Buddhism, like other religions, forbids its followers to commit murder. There are conditions why the person is said to have killed: a) The existence of a creature (human) who is still alive, even though he is in a coma; b) Then have the effort or intention to take his life; c) Then we act to do, and e) The result of our actions succeeded in eliminating the human being.

With this complete, it is perfect that that person has committed an offence of morality: killing. The religious view of this murder for any reason still violates religious precepts. If the family asks the doctor to perform Euthanasia, then religion leaves it back to the doctor to decide based on other appropriate reasons.

Buddhists often call on monks to come to pray for families who are temporarily in a coma, but the chants or prayers that monks recite are not meant to kill the life but to wish what is best for the patient and family. This narrative reflects how the religion wants its adherents to believe and pray for the best and not take the patient's life.

In the case of passive Euthanasia, even though the patient still survives even after removing the oxygen mask, passive Euthanasia still counts as an act of violation because there is an intention and the realization of that intention where intention (chetana) is the fulcrum of Buddhism. However, religion does not blame doctors if they do their job because of the professionalism needed and then return them.

If, in the end, it results in regret, which means that the act is not good, then religion hopes for the doctor to rethink and consider if he wants to take this action to fulfil his duties and responsibilities so that the doctor will not regret it. The difference that distinguishes the legalization of Euthanasia abroad and Indonesia is a 'made justification' that considers the happiness of patients and those around them to be prioritized, but truth and justification cannot be equated. The monk believes that religious adherents will more or less influence an individual's decision-making in his next course of action. People who are not religious do not mean immoral. They also have their views and considerations if, for Buddhists themselves and those who have studied the Dharma, their decision making will at least be considered according to the Dharma itself teachings.

The level of knowledge in this study is that respondents can know Euthanasia and its development. Knowledge assessed from 
respondents is related to understanding, influencing factors, the knowledge behind patients with terminal and mental illnesses and legal status.

Respondents in this study amounted to 72 people. The category of having good knowledge is respondents with a questionnaire score of $14-20$ points, those who enter sufficient knowledge are respondents with a questionnaire score of 713 points, and those who enter the category of lack of knowledge are respondents with a questionnaire score of less than or equal to 6.

From the level of knowledge analysis, the majority of respondents (79.2\%) have a sufficient level of knowledge. A study conducted in Spain by Velasquez et al. using medical personnel as respondents showed that $59.1 \%$ of respondents had good knowledge about Euthanasia [30]. It shows that the description of the level of student knowledge about Euthanasia is still relatively low but based on research conducted by Demedts et al. on Euthanasia [31] got a score of $62.5 \%$ of respondents having a sufficient level of knowledge. This percentage can then be seen to increase in 2017 UKI FK students. Respondents who have a good level of knowledge are still relatively low at $20 \%$.

The research shows that the results are divided into two by respondents: attitudes about the legalization of Euthanasia in Indonesia and individual attitudes about Euthanasia. 12\% of respondents strongly agree, and 34.2\% agree that terminal patients should be given the freedom to perform Euthanasia. It is in tandem with the respondents' agreement regarding student approval if Euthanasia is an alternative to end the patient's suffering as much as $8.3 \%$ strongly agree and $30 \%$ agree on which then the respondent agrees that Euthanasia may be carried out after receiving full consent from the patient and family, which is $16.7 \%$ agree and $42.5 \%$ strongly agree.
The results showed a positive attitude in accepting Euthanasia and the actions taken, but the respondents' views turned out to have different attitudes when viewed individually. As many as $26.7 \%$ disagree, and $18.3 \%$ strongly disagree that they as medical personnel must help the patient end his life. Their view follows this disagreement as medical students who will then go to the field, and if the patient asks for Euthanasia, 38.3\% disagree and 9.2\% strongly disagree. Then on the attitude related to the condition, if Euthanasia is legalized in Indonesia, respondents tend to agree with the approval of the doctor's refusal to perform Euthanasia, which is $26.9 \%$ strongly agree and $39.5 \%$ agree.

Two different overall and personal views are visible, but the doubt value from respondents who settled on an average of 39 (29.61\%) person. The value is the majority, and there is a fundamental difference between agreeing and disagreeing. It shows that most respondents agree that Euthanasia is carried out in Indonesia but personally do not want themselves to do the action.

\section{CONCLUSION}

Through the research that has been carried out, some conclusions obtained are presented, including 1) FK UKI students class 2017 has $20 \%$ of respondents with good knowledge, $79 \%$ with sufficient knowledge and $1 \%$ with poor knowledge; b) The factor that most influences the mindset of Euthanasia is a review of the religious aspect; c) The 2017 UKI FK students did not agree that Euthanasia needed to be supported by the community but agreed that support needed to be given from medical personnel; d) Most of the 2017 UKI FK students agree with the implementation of Euthanasia in Indonesia but do not agree individually or personally for those who carry out these actions and agree that if Euthanasia is legalized, doctors have the right to refuse to take such actions; e) The attitude of agreeing to Euthanasia in Indonesia is based on a mindset that prioritizes the welfare and happiness of 
patients that young people tend to have today; and f) Individual disapproval of Euthanasia is influenced by the mindset of Euthanasia which still violates Indonesian norms in the form of legal norms and religious norms. Therefore, Euthanasia is an important lesson and brings this topic even more into the Bioethics and Health Law block so that the number of students' knowledge of Euthanasia will increase.

\section{Acknowledgement: None}

\section{Conflict of Interest: None}

\section{Source of Funding: None}

\section{REFERENCES}

1. Rana, Jamal S., Sadiya S. Khan, Donald M. Lloyd-Jones, and Stephen Sidney. "Changes in mortality in top 10 causes of death from 2011 to 2018." Journal of General Internal Medicine 36, no. 8 (2021): 2517-2518.

2. Sargolzaie, Narjes, Malek Kiani, Mohamad Salari, and Morteza Khosravi. "Top ten causes of death and life expectancy in Zahedan (South-East Iran) in 2014." Global journal of health science 9, no. 6 (2017): 135-144.

3. Soriano, Joan B., David Rojas-Rueda, Jordi Alonso, Josep M. Antó, Pere-Joan Cardona, Esteve Fernández, Alberto L. GarciaBasteiro et al. "The burden of disease in Spain: Results from the Global Burden of Disease 2016." Medicina Clínica (English Edition) 151, no. 5 (2018): 171-190.

4. Mroz, Sarah, Sigrid Dierickx, Luc Deliens, Joachim Cohen, and Kenneth Chambaere. "Assisted dying around the world: a status quaestionis." Annals of Palliative Medicine 10, no. 3 (2021): 3540-3553.

5. Dees, Marianne K., Myrra J. VernooijDassen, Wim J. Dekkers, Glyn Elwyn, Kris C. Vissers, and Chris van Weel. "Perspectives of decision-making in requests for euthanasia: a qualitative research among patients, relatives and treating physicians in the Netherlands." Palliative medicine 27, no. 1 (2013): 27-37.

6. Narayan, Chandrika. "First Child Dies by Euthanasia in Belgium." CNN News. September 17 (2016).
7. McDougall, Jennifer Fecio, and Martha Gorman. Euthanasia: A reference handbook. ABC-CLIO, 2008.

8. Britt, Crystal A. Dying in America: A historical analysis of physician-assisted suicide and euthanasia. California State University, Long Beach, 2012.

9. Steck, Nicole, Matthias Egger, Maud Maessen, Thomas Reisch, and Marcel Zwahlen. "Euthanasia and assisted suicide in selected European countries and US states: systematic literature review." Medical Care (2013): 938-944.

10. Keown, John. Euthanasia, ethics and public policy: an argument against legalisation. Cambridge University Press, 2018.

11. Wrigley, Anthony. "Euthanasia as lifeextension." Death rights: Regulating the ending of life. Abingdon: Routledge (2021).

12. Patil, Amit. "Euthanasia-Ethical and Legal Perspectives." age 1 (2013): 3.

13. Wrigley, Anthony. "Euthanasia as lifeextension." Death rights: Regulating the ending of life. Abingdon: Routledge (2021).

14. Cohen-Almagor, Raphael. Euthanasia in the Netherlands: the policy and practice of mercy killing. Vol. 20. Springer Science \& Business Media, 2004.

15. Akabayashi, Akira. "Euthanasia, assisted suicide, and cessation of life support: Japan's policy, law, and an analysis of whistle blowing in two recent mercy killing cases." Social Science \& Medicine 55, no. 4 (2002): 517-527.

16. Dierickx, Sigrid, Luc Deliens, Joachim Cohen, and Kenneth Chambaere. "Euthanasia in Belgium: trends in reported cases between 2003 and 2013." CMAJ 188, no. 16 (2016): E407-E414.

17. Andrew, Erin VW, Joachim Cohen, Natalie Evans, Arantza Meñaca, Richard Harding, Irene Higginson, Robert Pool, and Marjolein Gysels. "Social-cultural factors in end-of-life care in Belgium: a scoping of the research literature." Palliative medicine 27, no. 2 (2013): 131-143.

18. van Veen, Sisco MP, F. Weerheim, Menno Mostert, and J. J. M. van Delden. "Euthanasia of Dutch patients with psychiatric disorders between 2015 and 2017." J Ethics Ment Heal 10 (2018): 1-15.

19. Mehlum, Lars, Christian Schmahl, Ann Berens, Stephan Doering, Joost Hutsebaut, Andres Kaera, Ueli Kramer et al. "Euthanasia and assisted suicide in patients 
with personality disorders: a review of current practice and challenges." Borderline Personality Disorder and Emotion Dysregulation 7, no. 1 (2020): 1-7.

20. Raus, Kasper, Bert Vanderhaegen, and Sigrid Sterckx. "Euthanasia in Belgium: Shortcomings of the Law and Its Application and of the Monitoring of Practice." In The Journal of Medicine and Philosophy: A Forum for Bioethics and Philosophy of Medicine, vol. 46, no. 1, pp. 80-107. US: Oxford University Press, 2021.

21. Pereira, Jose. "Legalizing euthanasia or assisted suicide: the illusion of safeguards and controls." Current Oncology 18, no. 2 (2011): 38-45.

22. Jorm, Anthony F., Scott B. Patten, Traolach S. Brugha, and Ramin Mojtabai. "Has increased provision of treatment reduced the prevalence of common mental disorders? Review of the evidence from four countries." World Psychiatry 16, no. 1 (2017): 90-99.

23. Ziebertz, Hans-Georg. "Human Dignity, Religious Ethics or Hedonism-What Can Predict Young People's Attitudes in Germany Towards the Right to Life in the Cases of Euthanasia and Abortion?." In Euthanasia, Abortion, Death Penalty and Religion-The Right to Life and its Limitations, pp. 83-104. Springer, Cham, 2019.

24. O'Neill, Ciaran, Dermot Feenan, Carmel Hughes, and D. A. McAlister. "Physician and family assisted suicide: results from a study of public attitudes in Britain." Social science \& medicine 57, no. 4 (2003): 721731.

25. Annadurai, Kalaivani, Raja Danasekaran, and Geetha Mani. "'Euthanasia: Right to die with dignity'." Journal of family medicine and primary care 3, no. 4 (2014): 477.

26. Devins, Gerald M. "Death anxiety and voluntary passive euthanasia: Influences of proximity to death and experiences with death in important other persons." Journal of Consulting and Clinical Psychology 47, no. 2 (1979): 301.

27. Byrne, Barbara M., and Pierre Baron. "The Beck Depression Inventory: testing and cross-validating a hierarchical factor structure for nonclinical adolescents." Measurement and Evaluation in Counseling and Development (1993).

28. Stedman, Richard C. "Toward a social psychology of place: Predicting behavior from place-based cognitions, attitude, and identity." Environment and behavior 34, no. 5 (2002): 561-581.

29. Sherif, Muzafer. Group conflict and cooperation: Their social psychology. Psychology Press, 2015.

30. Crusat-Abelló, Ernest, and Paz FernándezOrtega. "Nurses knowledge and attitudes about euthanasia at national and international level: A review of the literature." Enfermería Clínica (English Edition) (2021).

31. Demedts, Dennis, Marc Roelands, Julien Libbrecht, and Johan Bilsen. "The attitudes, role \& knowledge of mental health nurses towards euthanasia because of unbearable mental suffering in Belgium: A pilot study." Journal of psychiatric and mental health nursing 25, no. 7 (2018): 400-410.

How to cite this article: Wijoyo S. Overview of mindset and attitudes of 2017 FK UKI students about euthanasia. Int J Health Sci Res. 2021; 11(10): 353-364. DOI: https://doi.org/10.52403 /ijhsr.20211046 